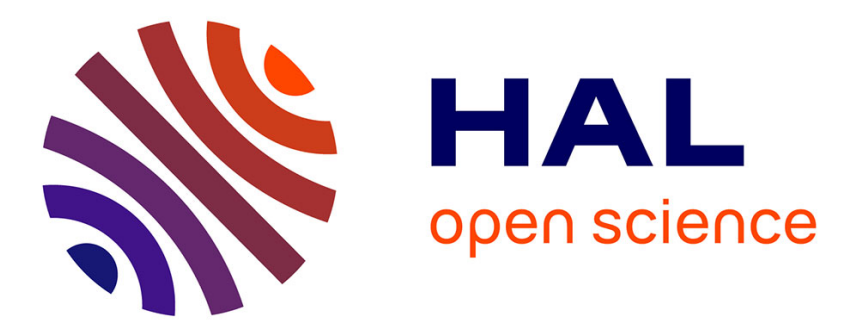

\title{
Vitamin D receptor variants and breast cancer risk in the Polish population
}

P. Gapska, R. J. Scott, P. Serrano-Fernandez, T. Huzarski, T. Byrski, J. Kladny, J. Gronwald, B. Górski, C. Cybulski, J. Lubinski, et al.

\section{- To cite this version:}

P. Gapska, R. J. Scott, P. Serrano-Fernandez, T. Huzarski, T. Byrski, et al.. Vitamin D receptor variants and breast cancer risk in the Polish population. Breast Cancer Research and Treatment, 2008, 115 (3), pp.629-633. 10.1007/s10549-008-0107-1 . hal-00478246

\section{HAL Id: hal-00478246 \\ https://hal.science/hal-00478246}

Submitted on 30 Apr 2010

HAL is a multi-disciplinary open access archive for the deposit and dissemination of scientific research documents, whether they are published or not. The documents may come from teaching and research institutions in France or abroad, or from public or private research centers.
L'archive ouverte pluridisciplinaire HAL, est destinée au dépôt et à la diffusion de documents scientifiques de niveau recherche, publiés ou non, émanant des établissements d'enseignement et de recherche français ou étrangers, des laboratoires publics ou privés. 


\title{
Vitamin D receptor variants and breast cancer risk in the Polish population
}

\author{
P. Gapska $\cdot$ R. J. Scott $\cdot$ P. Serrano-Fernandez $\cdot$ \\ T. Huzarski · T. Byrski · J. Kładny $\cdot$ J. Gronwald · \\ B. Górski · C. Cybulski · J. Lubinski · T. Dębniak
}

Received: 13 June 2008/Accepted: 13 June 2008/Published online: 29 June 2008

(C) Springer Science+Business Media, LLC. 2008

\begin{abstract}
The aim of the study was to determine whether four VDR gene single nucleotide polymorphisms (SNPs: rs1544410, rs731236, rs10735810 and rs4516035) are associated with breast cancer risk in Polish population. Two independent series of female patients were employed: 960 consecutive breast cancer cases, and 800 unselected early onset cases diagnosed under the age of 51 . The control group for the consecutive breast cancer cases consisted of 960 healthy, age-matched women with a negative cancer family history. 550 healthy women, aged 51 or less, with negative cancer family history were selected as the independent controls for the early onset breast cancer cases. The frequencies of the VDR polymorphisms in the unselected cases when compared to the respective control population failed to reveal any association between the individual SNPs and disease. Examination of the group of early-onset patients, revealed an association between rs10735810 and increased breast cancer risk. Heterozygous carriers for the change had an OR $=1.73(95 \%$ CI 1.33-2.26, $P<0.0001)$
\end{abstract}

P. Gapska - P. Serrano-Fernandez - T. Huzarski - T. Byrski ·

J. Gronwald · B. Górski · C. Cybulski · J. Lubinski .

T. Dębniak $(\square)$

Department of Genetics and Pathology, International Hereditary

Cancer Center, Pomeranian Medical University, Połabska 4,

70-115 Szczecin, Poland

e-mail: debniak@sci.pam.szczecin.pl

\section{R. J. Scott}

Discipline of Medical Genetics, Faculty of Health,

University of Newcastle, Newcastle, Australia

R. J. Scott

Hunter Medical Research Institute, Newcastle, Australia

J. Kładny

Department of Oncological Surgery, Pomeranian Medical

University, Szczecin, Poland and homozygous carriers OR $=2.34$ (95\% CI 1.71-3.21, $P<0.0001)$. The remaining three examined SNPs failed to show any association with disease risk. In summary, this study has identified an association between the VDR gene and early onset breast cancer risk in the Polish population.

Keywords Breast cancer - Vitamin D receptor

\section{Introduction}

The role of vitamin D and its receptor and the risk of breast cancer have not been completely elucidated and the reported data thus far are inconsistent. Studies that focus on the vitamin D receptor (VDR) suggest that polymorphic variants are associated with a change in the risk of developing breast cancer [1-3] but epidemiological evidence, which focuses on serum levels of $25(\mathrm{OH})_{2} \mathrm{D}_{3}$ and the active form of the vitamin, $1-25(\mathrm{OH})_{2} \mathrm{D}_{3}$ remain equivocal. Biological studies of $1-25(\mathrm{OH})_{2} \mathrm{D}_{3}$ indicate that it has anti-proliferative effects and therefore may be protective against tumour development [4]. Alterations in the bioavailability of $1-25(\mathrm{OH})_{2} \quad \mathrm{D}_{3}$ may as a consequence adversely affect the risk of breast cancer. Access of $1-25(\mathrm{OH})_{2} \mathrm{D}_{3}$ is mediated by the VDR and many reports have focused on identifying polymorphisms in this gene that may influence the kinetics of this process [5-8].

The VDR gene is located on chromosome 12q12-q14. It contains a minimum of five promoter regions [4] and is comprised of eight coding exons and six untranslated exons [7]. The gene is ubiquitously expressed intracellularly and belongs to the steroid/retinoid super-family of nuclear receptors that mediate the effects of $1-25(\mathrm{OH})_{2} \mathrm{D}_{3}$ which interact with D-response elements in the promoter regions of genes controlled by vitamin D [9-11]. 
The VDR gene harbours approximately 200 polymorphisms some of which are linked to differences in $1-25(\mathrm{OH})_{2}$ $\mathrm{D}_{3}$ uptake and therefore can be considered as candidate disease risk variants. The three most commonly investigated polymorphisms in VDR for cancer associations are located in exon 2 (rs10735810/rs2228570 or FokI), intron 8 (rs 1544410 or BsmI), and exon 9 (rs731236 or TaqI). The wild type protein is known as the M1 form. The polymorphism located in exon 2 is associated with a second methionine start site that results in a shorter protein receptor known as the M4 form [12]. The two polymorphisms in intron 8 and exon 9 are in linkage disequilibrium and appear to be associated with the binding kinetics of the receptor to $1-25(\mathrm{OH})_{2} \mathrm{D}_{3}$ [1]. The fourth SNP, rs4516035 located in the promoter region of the VDR gene, has not been studied among cancer patients so far.

In this report we have genotyped on a series of consecutively collected breast cancer patients of any age $(n=960)$ and a second independent group of breast cancer patients $(n=800)$ all of whom were under 51 years of age at the time of their diagnosis of disease. The VDR allele frequencies were compared to an age matched cohorts of healthy women who did not have a family history of breast cancer.

\section{Materials and methods}

Breast cancer patients

Two groups of breast cancer patients were included in this study. One group consisted of 960 consecutive prospectively ascertained female invasive breast cancer patients with a mean age of diagnosis of 56.5 years, (range 25-88), and a second independent group of 800 prospectively ascertained early onset breast cancer patients all under the age of 51 years, with a mean age of 44.2 years (range 21-50). All women were ascertained from the City of Szczecin and surrounding regions and collected between the years 2002 and 2008. All breast cancer cases were initially identified from the cancer register of the International Hereditary Cancer Center, located in Szczecin.

The study was approved by the ethics committee of the Pomeranian University. The patient was invited to participate in person during her hospital stay or through a mailed invitation. Participation rates exceeded $75 \%$. During the interview the goals of the study were explained, informed consent was obtained, genetic counseling was given and a blood sample was taken for DNA analysis. A detailed family history of cancer was taken (first, and second-degree relatives included) and a risk factor questionnaire was completed. The medical record and pathology report were reviewed.
Controls

Two control groups were established. The first group consisted of 960 healthy women (a mean age 56.5 years, range 25-88) who had a negative cancer family history and were matched for age ( \pm 2 years) with consecutive breast cancer cases. The second group consisted of 550 healthy women under the age of 51 who had a negative cancer family history (mean age 45.3 , age range 22-50). All women were ascertained from the City of Szczecin and surrounding regions and collected between the years 2007 and 2008 .

The healthy adults were assessed as having a negative cancer family history after answering a questionnaire about their family's medical history which was part of a population based study of the 1.5 million residents of West Pomerania to identify familial aggregations of malignancies performed recently by our center. The participation rate for "matched" controls was 50\%. During the interview the goals of the study were explained, informed consent was obtained, genetic counseling was given and a blood sample was taken for DNA analysis. A detailed family history of cancer was taken (first and second-degree relatives included) and a risk factor questionnaire was completed detailing sun exposure and occupation. Individuals affected with any malignancy or with cancers diagnosed among first- or second degree relatives were excluded from the current study control group.

In order to ensure comparability of the control groups, the allele frequencies of the VDR alleles were estimated separately for adults.

\section{Methods}

DNA samples were obtained from peripheral blood of individuals. All the VDR polymorphisms were analyzed by real- time PCR, using the LightCycler480 from Roche.

The analyses were performed using TaqMan(R) genotyping assay, consisting of sequence specific primers and oligonucleotide fluorescent labeled probes, which enabled amplification of examined fragments and further allele discrimination.

\section{Statistics}

In order to evaluate whether the VDR allele variants were associated with breast cancer risk, we performed a study consisting comparison of the allele frequencies the VDR variants between cases groups and the control groups.

Moreover, consecutive breast cancer patients and the control group consisting of adults were examined in two variants, under and over 50-year-old of individuals, thus taking into account gene-environment interactions. 
All the estimated results were assessed using a two-tailed Chi-squared test with Yates correction.

The combination of four SNPs generates sixteen possible haplotypes. The relative haplotype frequencies were estimated using the genetic statistical software package haplo.stats for $\mathrm{R}$ (http://cran.r-project.org/src/contrib/ Descriptions/haplo.stats.html) as developed by Schaid et al. [13]. The haplotype frequencies are estimated with the help of generalized linear models (GLMs) separately for cases and controls and then compared. The use of GLMs instead of the more extended expectation-maximization (EM) algorithm has the advantage of providing efficient score statistics both for global tests and haplotypespecific tests. Empiric $P$-values are computed based on 1000 simulations (permutations).

Linkage disequilibrium between the four SNPs was analyzed with the software JLIN (Java LINkage disequilibrium plotter) as developed by Carter et al. [14].

\section{Results}

Cases and controls had similar mean ages at enrolment of the study and all were of Polish ancestry. There were no significant differences in the allele frequencies of the VDR variants in the adults and newborns (data not shown) thereby indicating the stabile nature of the variants in the Polish population. This can be used as a measure to exclude changes in allele distributions in the Polish population in different age subgroups.

There were no differences in the frequencies of the examined SNPs between two adult control groups $(\mathrm{OR}=$ 1.0, $P>0.05)$.

The assessed allele distributions for all analysed VDR SNPs were in Hardy-Weinberg equilibrium for both the breast cancer and control groups.
The frequencies of the VDR polymorphisms in the unselected breast cancer group when compared to the respective control population failed to reveal any association between the individual SNPs and disease (see Table 1).

Examination of the second group of patients, all diagnosed with breast cancer under the age of 51 years did, however, reveal a more complex relationship with the VDR gene. Three of the four SNPs failed to show any association with disease risk, these being rs1544410, rs731236 and rs 4516035. An association was found to exist between rs10735810 and disease risk. Patients heterozygous for the change had an OR of 1.73 (95\% CI 1.33-2.26, $P<0.0001)$ and breast cancer patients homozygous for this polymorphism had an OR of 2.34 (95\% CI 1.71-3.21, $P<0.0001)$ (see Table 2). Patients harbouring one or more of the variant alleles did not have any difference in their average age of disease diagnosis compared to patients who did not harbour this polymorphism.

Linkage disequilibrium tests revealed similar results to studies of other populations in that rs1544410 and rs731236 were in linkage disequilibrium with each other (LR-Test, 1000 iterations, $P<0.0001)\left(\mathrm{R}^{2}=0.88 ; \mathrm{D}=\right.$ 0.96). Haplotype analysis was performed for these two SNPs on the unselected consecutively collected breast cancer group and independently on the group of breast cancer patients diagnosed less than 51 years of age. The results of this analysis reveal that the A-T haplotype of rs1544410 and rs731236 appears to be associated with a decrease in breast cancer risk in the consecutively collected breast cancer patients (OR 0.31 95\% CI 0.15-0.63, $P=0.0003$ ), however, the actual number of patients harbouring the "disease risk" haplotype was small and it could therefore be a type 1 statistical error. No other possible haplotypes were found to be over- and underrepresented in the unselected consecutively collected breast
Table 1 The frequencies of the VDR polymorphisms in the consecutive breast cancer cases and matched controls

\begin{tabular}{|c|c|c|c|}
\hline & $\begin{array}{l}\text { Consecutive breast cancer } \\
\text { cases }(\Sigma 960)\end{array}$ & Control group $(\Sigma 960)$ & $\mathrm{OR}$ and $P$ value \\
\hline \multirow[t]{3}{*}{ rs 1544410} & CC-361/910 (39.67\%) & CC-370/920 (40.22\%) & - \\
\hline & CT-420/910 (46.15\%) & CT-420/920 (45.65\%) & $1.022 ; 0.8547$ \\
\hline & TT-129/910 (14.18\%) & TT-130/920 (14.13\%) & $1.025 ; 0.8077$ \\
\hline \multirow[t]{3}{*}{ rs731236 } & AA-377/909 (41.47\%) & AA-380/890 (42.70\%) & - \\
\hline & AG-406/909 (44.66\%) & AG-408/890 (45.84\%) & $1.003 ; 0.9762$ \\
\hline & GG-125/909 (13.75\%) & GG-102/890 (11.46\%) & $1.235 ; 0.1640$ \\
\hline \multirow[t]{3}{*}{ rs10735810 } & GG-312/945 (33.02\%) & GG-300/948 (31.65\%) & - \\
\hline & GA-451/945 (47.72\%) & GA-461/948 (48.63\%) & $0.9407 ; 0.5585$ \\
\hline & AA-182/945 (19.26\%) & AA-187/948 (19.73\%) & $0.9358 ; 0.6149$ \\
\hline \multirow[t]{3}{*}{ rs 4516035} & TT-260/958 (27.14\%) & TT-272/953 (28.54\%) & - \\
\hline & CT-497/958 (51.88\%) & CT-485/953 (50.89\%) & $1.072 ; 0.5183$ \\
\hline & CC-201/958 (20.98\%) & CC-197/953 (20.67\%) & $1.067 ; 0.6227$ \\
\hline
\end{tabular}


Table 2 The frequencies of the VDR polymorphisms in the early-onset breast cancer cases and control group

\begin{tabular}{llrl}
\hline & $\begin{array}{l}\text { Early-onset breast } \\
\text { cancer cases }(\Sigma 800)\end{array}$ & Control group $(\Sigma 550)$ & OR and $P$ value \\
\hline rs1544410 & CC-308/718 $(42.90 \%)$ & CC-152/374 $(40.64 \%)$ & \multicolumn{1}{l}{ - } \\
& CT-318/718 (44.29\%) & CT-174/374 (46.52\%) & $0.9019 ; 0.4505$ \\
rs731236 & TT-92/718 (12.81\%) & TT-48/374 (12.83\%) & $0.9459 ; 0.7848$ \\
& AA-312/768 (40.63\%) & AA-236/546 (43.22\%) & - \\
& AG-348/768 (45.31\%) & AG-251/546 (45.97\%) & $1.049 ; 0.6907$ \\
rs10735810 & GG-108/768 (14.06\%) & GG-59/546 (10.81\%) & $1.385 ; 0.0754$ \\
& GG-160/791 (20.23\%) & GG-175/536 (32.65\%) & - \\
rs4516035 & GA-402/791 (50.82\%) & GA-254/536 (47.39\%) & $1.731 ; P<0.0001$ \\
& AA-229/791 (28.95\%) & AA-107/536 (19.96\%) & $2.341 ; P<0.0001$ \\
& TT-225/799 (28.16\%) & TT-145/536 (27.05\%) & - \\
& CT-416/799 (52.07\%) & CT-278/536 (51.87\%) & $0.9643 ; 0.7828$ \\
& CC-158/799 (19.77\%) & CC-113/536 (21.08\%) & $0.9011 ; 0.5224$ \\
\hline
\end{tabular}

cancer cases. Haplotype analysis of the patients diagnosed under the age of 51 years failed to reveal any association to disease for all possible combinations of the four polymorphisms studied. There was no difference in the frequency of the A-T haplotype of rs1544410 and rs731236 in the early onset breast cancer patients.

\section{Discussion}

There is a growing body of evidence that suggests variation in the level of vitamin D and polymorphisms in its receptor are associated with an altered risk of malignancy. The evidence to date for breast cancer, however, remains controversial as there are not only discrepancies between plasma concentrations of vitamin $\mathrm{D}$ and breast cancer risk but also the role of VDR as a risk determinant [15]. The VDR is highly polymorphic and it is currently not known how many polymorphisms are associated with disease nor the level of contribution of each of them. In addition to variance in the bioavailability of $1-25(\mathrm{OH})_{2} \mathrm{D}_{3}$ few studies have focused on whether or not different sub-categories of patients have the same or different levels of disease risk for each of the VDR variants. Clearly, there are a series of confounding factors that impact on an assessment of the role of vitamin D or its receptor. This report focuses on genetic factors that may influence disease risk. Due to the nature of how the patients were ascertained for this study it is impossible to correct for any environmental factor that may be implicated in breast cancer development.

The results of our investigation in unselected breast cancer cases suggest that neither vitamin D nor its receptor contribute significantly to disease risk. Even though, using haplotype analysis suggests that there may be an association we consider this unlikely at this stage since too few cases were identified carrying the "protective" allele. Nevertheless, since we did not examine a larger number of the 200 or more polymorphisms in the VDR gene we can not exclude the possibility that there are other disease associated alleles that affect the likelihood of breast cancer.

With respect to early onset breast cancer risk this is the first large study to identify an association with the M4 form of the vitamin D receptor. It appears that the shorter M4 form of the receptor is associated with an increased risk of breast cancer by virtue of its over-representation in early onset breast cancer patients. Importantly, the predicted presence of both the M4 and M1 forms of the protein were found to be associated with a modest increase in breast cancer risk which became more apparent in homozygote variant carriers, indicating a linear relationship between the three states of the gene. Since this effect was observed only in early onset breast cancer patients and not in the unselected population of patients, it suggests that the underlying pathogenesis of disease is different between the two groups. An important difference between rs10735810 in VDR and the other polymorphisms studied is that this SNP is not in linkage disequilibrium with any other SNP, thereby setting it apart from the other commonly investigated SNPs $[1,2,4]$. This suggests that any affect identified is most likely to be a result of the change imparted by this polymorphism on the functional protein. The M4 form of the receptor has been reported to be more potent than the longer M1 form as it has greater transactivation capacity as a transcription factor [4]. This suggests that increased transactivation in itself may not be sufficient to initiate disease but is capable of promoting disease development. As a consequence of the differences between the M4 and M1 forms of VDR, bone mineral density has been shown to be higher in women harbouring the SNP that is associated with the M4 form [5, 12, 16-18]. Bone mineral density has been associated with an increased risk of breast cancer [19-24] and this may explain the over-representation of this form of the receptor in the breast cancer patients 
diagnosed under the age of 51 years. This is especially important in younger women since in older women there is generally a reduced production of cholecalciferol in the skin in association with a reduction in the levels of estrogen and consequently decreased metabolic activation of vitamin D and expression of VDR.

In summary, this study has identified an association between the VDR gene and early onset breast cancer risk in the Polish population. Further work is required to evaluate the relationship between vitamin $\mathrm{D}$ and calcium intake in relation to breast cancer risk in pre-menopausal women.

\section{References}

1. Guy M, Lowe LC, Bretherton-Watt D et al (2004) Vitamin D receptor gene polymorphisms and breast cancer risk. Clin Cancer Res 10:5472-5481. doi:10.1158/1078-0432.CCR-04-0206

2. Trabert B, Malone KE, Daling JR et al (2007) Vitamin D receptor polymorphisms and breast cancer risk in a large population-based case-control study of Caucasian and African-American women. Breast Cancer Res 9(6):R84. doi:10.1186/bcr1833

3. Chen WY, Bertone-Johnson ER, Hunter DJ et al (2005) Association between polymorphisms in the vitamin $\mathrm{D}$ receptor and breast cancer risk. Cancer Epidemiol Biomarkers Prev 14(10): 2335-2339. doi:10.1158/1055-9965.EPI-05-0283

4. Uitterlinden AG, Fang Y, Jonce BJ et al (2004) Genetics and biology of vitamin D receptor polymorphisms. Gene 338:143156. doi:10.1016/j.gene.2004.05.014

5. Gross C, Ecceleshall TR, Malloy PJ et al (1996) The presence of a polymorphism at the translation initiation site of the vitamin D receptor gene is associated with low bone mineral density in postmenopausal Mexican-American women. J Bone Miner Res 11:1850-1855

6. Miyamoto K, Kesterson RA, Yamamoto H et al (1997) Structural organization of the human vitamin D receptor chromosomal gene and its promoter. Mol Endocrinol 11:1165-1179. doi:10.1210/ me.11.8.1165

7. Saijo T, Naito E, Ito M et al (1991) Therapeutic effect of sodium dichloroacetate on visual and auditory hallucinations in a patient with MELAS. Neuropediatrics 22:166-167

8. Schurzenbecker L, Scardaville B, Kratzeisen C et al (1994) Isolation and analysis of cDNA encoding a naturally occurring truncated form of the human vitamin D receptor. In: Bouilon $\mathrm{R}$, Norman A, Thomasset M (eds) Vitamin D: a pluripotent steroid hormone: structural studies, molecular endocrinology and clinical applications. Walter de Gruyter, Berlin, pp 253-257

9. Scott CM, Narasimha S, WenRong X, Rahul R (2001) Why do we need a three-dimensional architecture of the ligand-binding domain of the nuclear $1 \alpha, 25$-dihydroxyvitamin $\mathrm{D}_{3}$ receptor? Steroid 66:189-2001. doi:10.1016/S0039-128X(00)00134-3
10. Haussler MR, Whitfield GK, Haussler CA et al (1998) The nuclear vitamin receptor: biological and molecular regulatory properties revealed. J Bone Miner Res 13:325-349. doi:10.1359/ jbmr.1998.13.3.325

11. Norman AW (1998) Receptors for $1 \alpha, 25(\mathrm{OH})_{2} \mathrm{D}_{3}$ : past, present and future. J Bone Miner Res 13:1360-1369. doi:10.1359/jbmr. 1998.13.9.1360

12. Arai H, Miyamoto K-I, Taketani Y et al (1997) A vitamin D receptor gene polymorphism in the translation initiation codon: effect on protein activity and relation to bone mineral density in Japan women. J Bone Miner Res 12:915-921. doi:10.1359/ jbmr.1997.12.6.915

13. Schaid DJ, Rowland CM, Tines DE et al (2002) Score tests for association between traits and haplotypes when linkage phase is ambiguous. Am J Hum Genet 70:425-434. doi:10.1086/338688

14. Carter KW, McCaskie PA, Palmer LJ (2006) JLIN: a Java based linkage disequilibrium plotter. BMC Bioinformatics 7:60. doi: 10.1186/1471-2105-7-60

15. Lips P (2001) Vitamin D deficiency and secondary hyperparathyroidism in the elderly: consequences for bone loss and fractures and therapeutic implications. Endocr Rev 22:477-501. doi:10.1210/er.22.4.477

16. Harris SS, Eccleshall TR, Gross C et al (1997) The vitamin D receptor start codon polymorphism (FokI) and bone mineral density in pre- menopausal American black and white women. J Bone Miner Res 12:1043-1048. doi:10.1359/jbmr.1997.12.7. 1043

17. Arnes SK, Ellis KJ, Gunn SK et al (1999) Vitamin D receptor gene FokI polymorphism predicts calcium absorption and bone mineral density in children. J Bone Miner Res 14:740-746. doi: 10.1359/jbmr.1999.14.5.740

18. Gennari L, Becherini L, Mansani R et al (1999) FokI polymorphism at translation initiation site of the vitamin $\mathrm{D}$ receptor gene predicts bone mineral density and vertebral fractures in postmenopausal Italian women. J Bone Miner Res 14:1379-1386. doi:10.1359/jbmr.1999.14.8.1379

19. Biglia N, Defabiani E, Ponzone R et al (2004) Management of risk of breast carcinoma in postmenopausal women. Endocr Relat Cancer 11:69-83. doi:10.1677/erc.0.0110069

20. Zhang Y, Rosenberg L, Colton T et al (1996) Adult height and risk of breast cancer among white women in a case-control study. Am J Epidemiol 143:1123-1128

21. Buist DS, LaCroix AZ, Barlow WE et al (2001) Bone mineral density and breast cancer risk in postmenopausal women. J Clin Epidemiol 54:417-422. doi:10.1016/S0895-4356(00)00301-2

22. Nelson RL, Turyk M, Kim J et al (2001) Bone mineral density and the subsequent risk of cancer in the NHANES I follow-up cohort. BMC Cancer 2:22. doi:10.1186/1471-2407-2-22

23. Newcomb PA, Trentham-Dietz A, Egan KM et al (2001) Fracture history and fisk of breast cancer and endometrial cancer. Am J Epidemiol 153:1071-1078. doi:10.1093/aje/153.11.1071

24. Zhang Y, Kiel DP, Kreger BE et al (1997) Bone mass and the risk of breast cancer among postmenopausal women. N Engl J Med 336:611-617. doi:10.1056/NEJM199702273360903 